\title{
BLICKDIAGNOSE
}

\section{Dickdarm auf Abwegen!}

\section{Als ein 70-jähriger Patient wegen Thorax- schmerzen eingewiesen wurde, bot sich dem untersuchenden Arzt ein überraschender ab- domineller Befund: Unter der Haut fand sich ein schlauchartiges Gebilde, welches wie ein Stück Dickdarm imponierte. Hinweise für eine Bauchwandhernie bzw. ein Abdominaltrauma ergaben sich nicht. Wie lässt sich ein solcher Befund erklären?}

- Die Anamnese ergab, dass bei dem Patienten vor ca acht Jahren ein Ösophaguskarzinom diagnostiziert und anschließend operativ behandelt wurde. Eine ausgedehnte Resektion der Speiseröhre erfordert dann immer eine reparative oder rekonstruktive Funktionsplastik der Speiseröhre unter Verwendung eines Transplantates quasi als Ösophagusersatz, um die orale Nahrungsaufnahme zu ermöglichen.

Die einfachste Lösung, die jedoch nur bei einer begrenzten Resektion möglich ist, ist das transpleurale "Hochziehen" des Magens. Wenn dies aus anatomischen Gründen nicht möglich ist, besteht die Notwendigkeit für eine Ersatzplastik in Form einer retrosternalen Jejunuminterposition oder - wie bei diesem Patienten geschehen - einer subkutanen Koloninterposition. Abgesehen von einem ausgeprägten foetor ex ore ist der Patient von Seiten des operativen Eingriffes beschwerdefrei.

Keywords: esophageal carcinoma, esophagoplasty

- Dr. med. Peter Stiefelhagen, Hachenburg

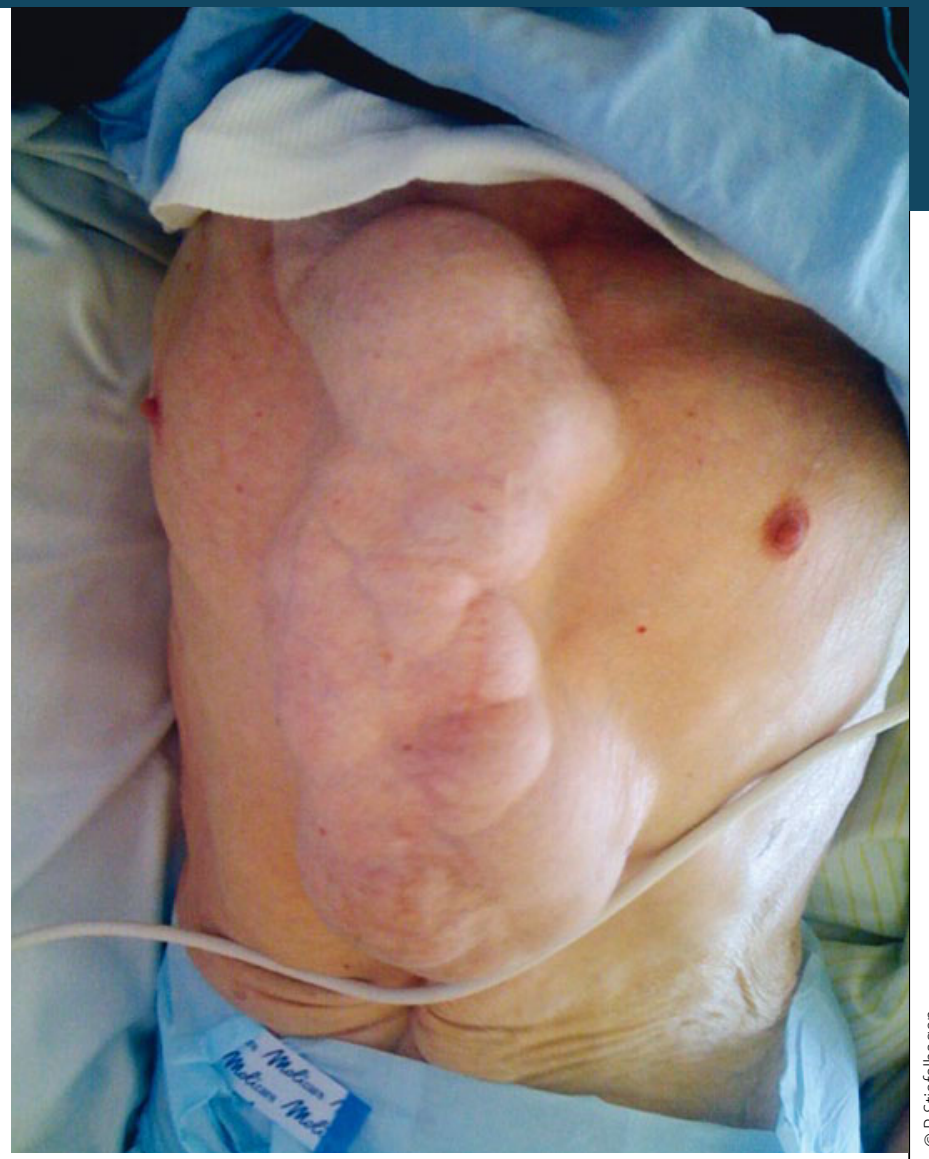

Ihr besonderer Fall?

\section{Stellen Sie uns Ihren Fall vor}

Sicher sehen auch Sie ab und an einen besonders eindrucksvollen Befund in Ihrer Praxis. Fotografieren Sie ihn, schreiben Sie uns unter dem Stichwort Blickdiagnose, bei Veröffentlichung erhalten Sie 100 Euro.

MMW-Fortschritte der Medizin

E-Mail: reinhold.manhart@springer.com

Fax: 089/203043-31424

\section{Info}

Unsere Blickdiagnosen finden Sie auch im Internet unter:

http://www.springermedizin.de/

blickdiagnosen-aus-der-praxis/307330.html 